DA
$\mathrm{D}$

I A L

UMR 225 IRD - Paris-Dauphine

\title{
Migrant network and immigrants' occupational mismatch
}

Isabelle CHORT 


\title{
MIGRANT NETWORK AND IMMIGRANTS' OCCUPATIONAL MISMATCH
}

\author{
Isabelle Chort \\ PSL, Université Paris-Dauphine, LEDa, UMR DIAL, 75016 Paris, France \\ IRD, UMR DIAL, 75010 Paris \\ isabelle.chort@dauphine.fr
}

Document de travail UMR DIAL

Avril 2013

\begin{abstract}
This paper defines new measures of horizontal and vertical mismatch based on the discrepancies between the skill content of occupations in which individuals have a self-assessed productive advantage and that of their actual job. Based on these definitions, this paper provides the first direct empirical test of the causal impact of networks on mismatch, in the particular case of immigrants. The data used are original survey data collected among 1,200 Senegalese migrants in four host countries. Potential endogeneity issues are dealt with by using migrants' ethnic and religious characteristics to instrument for network help to find a job.
\end{abstract}

Analyses show that migrants who obtained their job through migrant networks have a higher probability of horizontal mismatch. However, they have a lower probability of negative mismatch and thus seem to be protected from a loss in occupational status.

Key words: Occupational mismatch; networks; immigration; labor market; skill recognition.

\section{Résumé}

Ce papier présente de nouveaux indicateurs d'inadéquation professionnelle verticale et horizontale, définis à partir du décalage entre le niveau de qualifications associé au métier des individus et à leur emploi. Sur la base de ces définitions, ce papier est le premier à tester directement l'impact causal des réseaux sur l'inadéquation professionnelle, dans le cas particulier des immigrants. Les données utilisées sont des données d'enquêtes originales, collectées auprès de 1200 migrants sénégalais dans quatre pays de destination. Je traite les problèmes d'endogénéité potentiels en utilisant les caractéristiques ethniques et religieuses des migrants pour instrumenter le recours à l'aide du réseau pour trouver un emploi.

Cette analyse montre que les migrants qui ont obtenu leur emploi par leur réseau de migrants ont une probabilité plus élevée d'inadéquation professionnelle horizontale. En revanche, ils ont une probabilité moindre de déclassement professionnel, ce qui suggère que le réseau joue un rôle protecteur.

Mots Clés : Déclassement professionnel ; immigration; réseau migratoire ; marché du travail.

JEL Code: J24; J61; J62; F22 


\section{Introduction}

The impact of networks on job-search and labor-market outcomes has been much investigated since the founder work of Granovetter (1974). Networks first matter in the job-search process because they are expected to reduce asymmetries of information (Montgomery, 1991). They should thus improve the quality of the match between hiring firms and applying workers. Dustmann, Glitz, and Schönberg (2011) for example, who explore both theoretically and empirically the causes of ethnic segregation at the firm level, show that referrals by members of the same minority group reduce uncertainty about the productivity of job market candidates and explain higher wage offers made by the firm.

However, recent works seem to challenge this view: indeed, a specific trend in this literature, building on Montgomery (1991), investigates and models the impacts of network strength on wages. Goel and Lang (2009) focus in particular on the role of networks on job search outcomes of recent immigrants. By allowing migrants to use both formal job-search channels and informal ones (networks), they show that having accepted a job offer through the network has no theoretical impact on wages. Their main finding is that stronger networks are associated with lower network premiums, defined as the wage differential between jobs obtained through the networks and with formal search channels. Similarly, Bentolila, Michelacci, and Suarez (2010) find that jobs found through personal contacts return lower wages than jobs obtained through formal methods. They explain this finding by a poorer quality of the match. Indeed, the basic intuition of their model is that jobs obtained through social contacts may not be perfectly adapted to individuals' skills, given the limited number of occupations in which individuals have contacts who are likely to refer them for a job. To my knowledge, Bentolila, Michelacci, and Suarez (2010) is the only paper that specifically tackles the link between networks and occupational mismatch. However, the authors cannot provide a direct test of the predictions of their theoretical model for lack of direct observations of occupational mismatch, and they indirectly study the impact of networks on wages. 
Occupational mismatch is an even more acute issue for immigrants in host countries. According to the European Social Survey data covering 22 European countries and 76 immigrants' countries of origin for the 2000-2009 period, $22 \%$ of immigrants are overqualified for their job, while this is the case of only $13 \%$ of natives (Aleksynska and Tritah, 2011). Whereas immigrants' economic performance in destination countries is partly explained by migrants' self-selection (Borjas (1987) ; Chiswick (1999)), occupational mismatch of immigrants is also obviously related to the recognition at destination of the skills that they acquired in their country of origin.

Given the role played by migrant networks in the economic integration of immigrants in host countries, networks very likely affect occupational mismatch. The impact of migrant networks on job-search and labor market outcomes has indeed led to a sizable literature. In particular, Munshi (2003) shows that the size of the Mexican network in the U.S. increases the probability for a Mexican immigrant to be employed, and to get a better job in the non-agricultural sector, using rainfall in Mexico to instrument for network size at destination. Amuedo-Dorantes and Mundra (2007) find, in addition, a positive impact of networks on wage of Mexican immigrants in the U.S. However, no paper has yet addressed the impact of migrant networks on immigrants' occupational mismatch.

In addition, the prevailing approach of occupational mismatch in the empirical literature is almost exclusively focused on vertical mismatch, based on discrepancies between immigrants' educational attainment and the educational requirements of the jobs that they get in host countries, as illustrated by the widespread anecdotal evidence of PhD holders working as taxi drivers. Mismatch is indeed predominantly defined as over- or under-education in papers focusing on immigrants' mismatch (Chiswick and Miller (2009); Aleksynska and Tritah (2011)), following the more general labor literature (Di Pietro and Urwin (2006)) . Such an approach has two main limitations, notably as regards the analysis of migrants' occupational mismatch. First, focusing on vertical mismatch only, may eclipse part of a more complex reality. The original survey data used in this paper, 
that were collected among 1,200 Senegalese migrants in four destination countries, indeed reveal a high prevalence of other forms of mismatch, which I define as horizontal mismatch: $19 \%$ of these migrants work in a job or sector other than the one in which they have a productive advantage, even though both have similar skill requirements. Second, education-based definitions are not well adapted to low-educated populations, as could be the case of immigrant populations originated from developing countries. For such populations, these measures would in particular lead to underestimate mismatch by ruling out the possibility of occupational mismatch, including horizontal mismatch, for individuals with no formal education.

The data I use are part of the MIDDAS project ${ }^{1}$, and were collected among 1200 Senegalese migrants in four of the top destination countries of Senegalese: two European countries, France and Italy, and two West-African countries, Mauritania and Côte d'Ivoire. Both the sampling strategy based on the latest available census data in each host country and the data collection based on random contacting of immigrants in public areas were aimed at ensuring that the resulting sample of migrants is not selected, especially with respect to their insertion in migrant networks.

In this paper, I first overcome the double limitation of education-based definitions of vertical mismatch by providing new measures of mismatch based on the discrepancies between individuals' self-declared "profession" or "trade" (corresponding to the French notion of métier) and their actual occupation, using occupation codes and skill levels associated with each occupation from the 2008 International Standard Classification of Occupations (ISCO-08). I define vertical mismatch (either positive or negative) based on discrepancies between the level of skills required in the job in which the migrant declares that she has a productive advantage and those required in her actual job. Similarly, horizontal mismatch corresponds to the case of migrants having a job which does not match their self-declared productive advantage but which is ascribed the same skill level

\footnotetext{
${ }^{1}$ MIDDAS is three-year project standing for "Migration and development in Senegal: an empirical analysis using matched data on Senegalese migrants and their origin households (MIDDAS)" funded by the French Agence Nationale de la Recherche and the Agence Française de Développement.
} 
according to the ISCO-08 classification.

I then estimate the impact of network help to get a job on immigrants' both vertical and horizontal occupational mismatch. This paper implements instrumental variable methods to overcome the endogeneity biases resulting from the likely non-random choice of using informal job-search channels. Immigrants who obtained their job through the migrant network may indeed have an otherwise lower, or higher, unobserved ability than those who found a job using another channel. In order to estimate the causal impact of network help to find the current job on occupational mismatch, I use migrants' ethnic group and their belonging to the Mouride brotherhood to instrument for network help.

When the potential endogeneity of network use in the job-search process is not accounted for, I find that migrants who obtained their current job through the migrant network are less likely to suffer negative vertical mismatch in both regions, Europe and Africa, and are more likely to experience horizontal mismatch, though the latter result if significant in the two African countries only. When tackling the endogeneity issues by estimating an IV model, the protecting effect of network help against a loss in occupational status is confirmed, and the positive impact of network help on horizontal mismatch tends to become significant for European destinations too.

This paper first contributes to the literature on occupational mismatch by providing the first direct empirical estimation of the causal impact of networks on occupational mismatch, building on the recent job-search theoretical literature. Indeed, the link between networks and occupational mismatch is at the core of the model presented by Bentolila, Michelacci, and Suarez (2010). The authors assume in a static model that occupations in which workers have a productive advantage are not necessarily the ones in which they have social contacts. Workers with smaller networks may thus choose to sacrifice their productive advantage and accept a network offer in order to reduce unemployment duration. But although their model specifically tackle the question of productive mismatch, they cannot provide a direct test of their predictions for lack of appropriate data and use wage data instead. They find, on average, a negative impact of network-based search on 
wages. Using survey data containing information on both individuals' actual occupation and self-assessed productive advantage, I provide in this paper the first direct empirical test of the predictions of the model by Bentolila, Michelacci, and Suarez (2010), by exploring the relationship between network referrals and occupational mismatch, in the particular case of immigrants.

Second, this paper contributes to the occupational mismatch literature by introducing new definitions of both horizontal and vertical occupational mismatch based on discrepancies between individuals' self-assessed productive advantage and actual occupation. The mismatch literature indeed almost exclusively focuses on vertical mismatch which is based on education: mismatch is defined as over- or under-education (Chiswick and Miller (2009); Aleksynska and Tritah (2011)). Even the very few studies that address the issue of horizontal mismatch similarly define mismatch based on education: horizontal mismatch captures the discrepancies between an individual's field of education and her occupation (Robst (2007); Nordin, Persson, and Rooth (2010)).

Third, this paper contributes to the theoretical and empirical literature on the impact of migrant networks on immigrants' labor market outcomes in host countries. Although the question of the impact of migrant networks on employment or wages gave rise to substantial research (Munshi (2003); Amuedo-Dorantes and Mundra (2007)), no paper has yet addressed the impact of migrant networks on immigrants' occupational mismatch.

This paper more generally relates to the vast literature on the impact of migrant networks on job-search and labor market outcomes. The theoretical predictions regarding the role of networks in job-search model are mostly based on a comparison between formal and informal search methods (networks), and depend on assumptions about: the rate of arrival of job offers, which is for example assumed to be lower through the network than through formal search methods in Kugler (2003); the distribution of wage offers, which may differ depending on whether they are provided by networks or formal channels (Goel and Lang, 2009); the possibility for workers to use only one job-search method or compare offers obtained from different channels (as in Goel and Lang (2009)); the relative cost of 
network search which is assumed to be lower than formal methods search for example in Cahuc and Fontaine (2009). Most of the above mentioned papers do not specifically address the issue of migrant networks. Regarding the different channels for networks effects listed above, some specificities of migrant networks may be pointed. The rate of arrival of job offers through the network may in particular be higher and the relative cost of network search compared to formal search may be lower for immigrants. Indeed, access to formal search methods may be made more costly by the cultural distance and lead immigrants to rely more on informal network-based job search. Moreover, rejecting a job offer provided by personal contacts may be more costly than rejecting a formal offer, especially for immigrants since they may need network help only to get a job but also for example to find a housing or get over cultural barriers.

The rest of the paper is organized as follows. Section 2 describes the MIDDAS survey data and defines the mismatch and network variables that I use. Section 3 presents the empirical strategy and the instruments used. Section 4 reports and discusses the empirical findings and section 5 concludes.

\section{Data}

\subsection{Description of the survey}

The data used in this paper come from four surveys conducted among Senegalese migrants in 2009 and 2010, that are part of the MIDDAS project ${ }^{2}$. 1200 Senegalese were surveyed in four major destination countries: France, Italy, Mauritania and Côte d'Ivoire. The sampling design was based on the latest census data in each country to ensure sample

\footnotetext{
${ }^{2}$ This three-year project (2008-2011) entitled "International Migration and Development: an Analysis using Matched data on Migrants and Origin Households in Senegal (MIDDAS)" was funded by the French Agence Nationale de la Recherche (ANR) and the Agence Française de Développement (AFD). Overall coordination was carried out by a research team from the Institut de Recherche pour le Développement (IRD-DIAL), with fieldwork support from researchers from the Forum Internazionale ed Europeo di Ricerche sull' Imigrazione (FIERI) in Italy and the Agence Nationale de la Statistique et de la Démographie (ANSD) in Senegal. For futher details on the global objectives and the institutional setting of the MIDDAS project, see http://www.dial.prd.fr/dial_enquetes/dial_enquetes_middas.htm.
} 
representativeness. Fieldwork procedures and questionnaire used in each country were the same. We collected detailed information on migrants' employment characteristics, wage, education, as well as their networks and contacts.

Unemployment data at a disaggregate level are included as additional controls in some specifications restricted to the subsample of migrants in Europe. Data on unemployment rates at the department level for France (département) are taken from INSEE, and at the province level for Italy from Eurostat ${ }^{3}$.

\section{$2.2 \quad$ Variables}

Occupational mismatch is identified based on the discrepancies between migrants' answers to two distinct survey questions: a first question about their profession or trade, and a second question about their actual job ${ }^{4}$. The first question was intended at capturing individual comparative productive advantages and its formulation invited migrants to answer according to their self-assessed productive skills.

By comparing answers to these two questions and coding them using the 2008 International Standard Classification of Occupations (ISCO-08), I am able to further define vertical (negative) mismatch, when the migrant's actual job corresponds to a lower skill level than his declared comparative advantage and horizontal mismatch, when the migrant's actual job does not match her self-declared "profession" or "trade" but when both correspond to the same skill level ${ }^{5}$. The ISCO-08 skill level classification ranges from 1 (elementary occupations) to 4 (highest skill level) ${ }^{6}$. The mapping of ISCO-08 major groups to the four skill levels is reproduced in Appendix.

Two examples may help: a migrant who declares being an accountant (skill level 4) and is actually employed as a workman (skill level 1) experiences a negative mismatch.

\footnotetext{
${ }^{3}$ Disaggregate unemployment data were not available for the two African countries.

${ }^{4}$ The rationale behind these two questions was to capture the different notions, in French, of métier and emploi.

${ }^{5}$ Only 10 cases of positive vertical mismatch are observed (1\% of the sample). In the empirical application these 10 observations are pooled with horizontal mismatch.

${ }^{6}$ See http://www.ilo.org/public/english/bureau/stat/isco/isco08/index.htm
} 
However, being a self-declared tailor and working as a cook is regarded as an horizontal mismatch (both are classified at skill level 2). Importantly, discrepancies between the migrant's self-assessed productive advantage and actual job may capture in part a subjective inadequacy between a migrant's qualifications and the type of occupation he has.

As for network variables, I define a dummy variable that equals one when the migrant obtained her current job through the migrant network. The migrant network is here defined in a broad sense : it includes family members and non related Senegalese.

\subsection{Summary statistics}

Table 5 in Appendix presents summary statistics for individual characteristics, employment status and networks by destination (Europe and Africa). The main differences between migrants in Africa and in Europe concern education: the share of migrants with medium to high levels of education is much higher in France and Italy than in African countries. Consequently, the percentage of negative mismatch is very low in Mauritania and Côte d'Ivoire (2.1\%). Indeed, negative mismatch is negatively correlated with education since migrants with low educational attainments are more likely to declare that they have a comparative productive advantage in a job requiring one of the lowest skill levels, and therefore are unlikely to actually have an even less skilled job.

\section{Empirical specification}

As a first step, I explore the potential impact of the migrant network on the probability to experience occupational mismatch by estimating the following equation by a standard probit:

$$
M_{i}^{*}=\alpha_{0}+X_{i}^{\prime} \alpha_{1}+\alpha_{2} N H_{i}+\delta_{j}+\epsilon_{i}
$$


where $M_{i}^{*}$ denotes the latent mismatch status of migrant $i$ and is only observed as:

$$
M_{i}=\mathbb{1}_{\left\{M_{i}^{*}>0\right\}}
$$

where $N H_{i}$ is the network help dummy, and $X$ is a set of control variables including age, gender, education. $\delta_{j}$ are country fixed-effects. $M_{i}$ is here a generic notation for mismatch but two sets of equations are separately estimated, the dependent variable being alternately a dummy variable for horizontal and negative mismatch.

However, coefficients estimated by a standard probit are likely to be biased if unobserved variables drive both the probability to find a job through the network and the probability of mismatch. Note that endogeneity is likely to be more problematic for negative mismatch than for horizontal mismatch. It seems indeed more likely that unobserved characteristics of migrants would increase both their probability to use migrant networks in their job-search and their probability to get a less (or more) skilled job than the one for which they are best qualified, than merely get a different equally skilled job. Indeed, assume for example that migrants who turn to their network to find a job have on average higher unobservable skills, then they may also be less likely to experience a negative mismatch, whatever help they may receive from their network. But there is little reason to believe that they would be more or less likely to get a job requiring a comparable skill level, which does not match their comparative productive advantage. However such an assumption may be debated, and in the following, instrumental variable techniques are applied for both horizontal and negative mismatch.

\subsection{Instrumental variables estimation of networks effects}

\subsubsection{Instruments}

Since potential endogeneity issues may bias estimation results from standard probit regressions, I use an instrumental variable approach to properly identify the causal impact of migrant network help to get a job on occupational mismatch. The challenge is here to 
find variables which affect the probability to get a job through the network but have no impact on mismatch, other than through network help.

A first candidate instrument, which is expected be correlated with network help to find a job and arguably satisfying the exclusion restriction, is migrants' affiliation to the Mouride brotherhood. Indeed, socio-anthropological studies document the strength of network links in the widespread Mouride diaspora (see for example Bava (2003)). Being a member of the Mouride brotherhood is thus likely to increase the probability to get a job through the migrant network. On the other hand, religious brotherhood affiliation is not likely to affect migrants' status on the labor market in host countries, even less so in European countries of Christian tradition, where the Senegalese migrant population is homogeneously muslim. Indeed, being a Mouride could directly affect labor-market outcomes at destination mainly for the two following reasons. First, Mourides may be offered different kind of jobs by employers, which is not likely to be the case in Europe since potential employers are very unlikely to identify them as being different from nonMouride Senegalese. Second, Mourides may differ from non-Mourides and have particular unobserved characteristics that correlate with labor-market outcomes. However I make here the assumption that belonging to the Mouride brotherhood may affect migrants' probability of experiencing labor market mismatch in Europe only through networks effects. This assumption may seem rather strong: note however that I do not assume that belonging to the Mouride brotherhood does not affect a migrant's choice of sector or activity. Belonging to the Mouride brotherhood is indeed very likely correlated with unobserved characteristics affecting a migrant's attitude to work in general. What I assume is that given this attitude to work, belonging to the Mouride brotherhood has no effect, other than through the migrant network, on the probability to be mismatched, that is, on the observed discrepancies between a migrant's productive comparative advantage (which may well be affected by his religious practices) and its actual job.

A second candidate instrument is based on Senegalese ethnic groups. I define a dummy variable equal to one when the migrant is Wolof. The Wolof are the largest 
ethnic group in Senegal, with $43 \%$ of the population but their migration history is more recent than that of other Senegalese ethnic groups. Indeed, Senegalese migrations have deep historical roots but the first region of Senegal to participate in massive international migration was the Senegal River valley adjoining Mauritania and Mali, mainly populated by Halpulaar'en, as documented by Clark (1994), and Soninké. Wolof are thus expected to have smaller networks than other Senegalese ethnic groups, in particular in France which is the historic destination of Senegalese. On the other hand, being a member of the Wolof group is not expected to have a direct impact on job-market mismatch of Senegalese in Europe. Again, this assumption is not as strong as it might seem, since it is not assumed that ethnic group is uncorrelated with attitude towards work in general. Note however that the exclusion restriction may not necessarily be satisfied in the case in Africa, in particular in Mauritania since the Wolof account for almost 8\% of the Mauritanian population: cultural proximity or a common language could thus explain different labor-market outcomes. Note that the Mouride and Wolof variables are positively correlated: the influence of the Mouride brotherhood is indeed particularly present among the Wolof.

Since the exclusion restriction for both instruments is less likely to be satisfied for African destinations than for European ones, I focus on the subsample of migrants in France and Italy when implementing instrumental variable strategies.

\subsubsection{Instrumental variable (IV) estimation}

Although both the dependent variable (occupational mismatch) and the endogenous regressor (network help) are discrete, I first estimate a two-stages instrumental variable model, as a basis for comparison. The first-stage equation writes:

$$
N H_{i}^{*}=\beta_{0}+X_{i}^{\prime} \beta_{1}+\beta_{2} Z_{i}+\delta_{j}+\nu_{i}
$$


Where $N H_{i}$ is the latent network help status of migrant $i$ and is only observed as:

$$
N H_{i}=\mathbb{1}_{\left\{N H_{i}^{*}>0\right\}}
$$

with the same notations as above: $N H_{i}$ is a dummy variable equal to one for migrant $i$ if she found her current job through the migrant network. $X_{i}$ is a set of individual characteristics including gender, age and education dummies, $\delta_{j}$ are country fixed-effects, and $Z_{i}$ the instrument (the Mouride or Wolof dummy). $\nu_{i}$ is the individual error term.

The second-stage equation follows the form:

$$
M_{i}^{*}=\alpha_{0}+X_{i}^{\prime} \alpha_{1}+\alpha_{2} \widehat{N H_{i}}+\delta_{j}+\epsilon_{i}
$$

where $M_{i}^{*}$ is the latent mismatch status of migrant $i$ and is only observed as

$$
M_{i}=\mathbb{1}_{\left\{M_{i}^{*}>0\right\}}
$$

where $M_{i}$ is the probability for migrant $i$ to experience occupational mismatch, either horizontal or negative, depending on the specification. $X_{i}$ and $\delta_{j}$ are the same as above, and $\widehat{N H_{i}}$ is the predicted probability to have been helped by the network, obtained from stage 1 regression.

\subsubsection{Bivariate probit}

Since both the dependent variable and the endogenous regressor are dummy variables, I simultaneously estimate the following two equations with a bivariate probit:

$$
\begin{aligned}
& N H_{i}^{*}=\beta_{0}+\beta_{1}^{\prime} X_{i}+\beta_{2}^{\prime} Z_{i}+\delta_{j}+\nu_{i} \\
& M_{i}^{*}=\alpha_{0}+\alpha_{1}^{\prime} X_{i}+\delta_{j}+\epsilon_{i}
\end{aligned}
$$


with the same notations as above, $N H_{i}^{*}$ and $M_{i}^{*}$ being latent continuous variables and $N H_{i}$ being an indicator variable for having obtained one's job through the migrant network, which equals one when $N H_{i}^{*}>0$. Similarly, the indicator variable $M_{i}$ for mismatch, alternately horizontal and negative, equals one when $M_{i}^{*}>0$.

\section{Results}

\subsection{Probit estimates of mismatch}

My sample of interest is made of the 967 migrants of the initial sample that are currently employed (79.6\% of the overall sample).

Results from standard probit estimations of horizontal and negative mismatch equations are presented in table 1. Migrants from all four surveyed countries are pooled. These results suggest that network help has a contrasted impact on the different types of mismatch: indeed, finding a job through the migrant network seems to increase the probability of horizontal mismatch but to decrease the probability of negative mismatch.

Being a man and age at arrival in the host country are positively and significantly correlated with horizontal mismatch. Moreover horizontal mismatch is significantly higher in Italy than in France. This result is explained by the greater specialization of Senegalese migrants in Italy in informal trade. The significantly lower probability of negative mismatch in Mauritania and Côte d'Ivoire than in France is a direct consequence of the smaller share of migrants with secondary and tertiary education in Africa.

Table 2 presents the same regressions depending on the broad host region: results of probit regressions for horizontal and negative mismatch run on the subsample of migrants in France and Italy are presented in column (1) and (2), and results for horizontal mismatch in African countries in column (3). Due to the small proportion of negative mismatch in Mauritania and Côte d'Ivoire, the equation for negative mismatch in Africa cannot be consistently estimated. The breakdown of migrants according to their location suggests that network help has a similar impact on horizontal mismatch in Africa and 
Table 1: Probit estimates for horizontal and negative mismatch; whole sample

(1)

$(2)$

Horizontal mismatch (d) Negative mismatch (d)

\begin{tabular}{lcc}
\hline Network help & $0.254^{*}$ & $-0.396^{*}$ \\
Migration duration & $(0.136)$ & $(0.208)$ \\
& $0.015^{* *}$ & -0.003 \\
Male (d) & $(0.006)$ & $(0.008)$ \\
& $0.266^{*}$ & -0.099 \\
Age at arrival & $(0.138)$ & $(0.156)$ \\
& $0.020^{* * *}$ & 0.001 \\
Intermediate or vocational secondary degree (d) & $(0.007)$ & $(0.009)$ \\
& 0.134 & $0.277^{+}$ \\
Secondary degree (bac) (d) & $(0.147)$ & $(0.182)$ \\
& $0.312^{*}$ & $0.378^{+}$ \\
University degree (d) & $(0.189)$ & $(0.237)$ \\
& -0.050 & $0.418^{* *}$ \\
Italy (d) & $(0.190)$ & $(0.211)$ \\
& $0.229^{+}$ & 0.190 \\
Mauritania (d) & $(0.154)$ & $(0.167)$ \\
Cote d'Ivoire (d) & -0.073 & $-0.943^{* * *}$ \\
Constant & $(0.173)$ & $(0.268)$ \\
& 0.041 & $-0.487^{* *}$ \\
Observations & $(0.163)$ & $(0.210)$ \\
Pseudo $R^{2}$ & $-2.223^{* * *}$ & $-1.321^{* * *}$ \\
\hline Roburt stangrd & $(0.277)$ & $(0.317)$ \\
\hline
\end{tabular}

Robust standard errors in parentheses

${ }^{+} p<0.15,{ }^{*} p<0.10,{ }^{* *} p<0.05,{ }^{* * *} p<0.01$

(d) for dummy variables 
Table 2: Probit estimates for horizontal and negative mismatch: Europe and Africa

\section{Europe}

(1)

$(2)$

(3)

\begin{tabular}{|c|c|c|c|}
\hline Network help & $\begin{array}{c}0.112 \\
(0.192)\end{array}$ & $\begin{array}{c}-0.373^{+} \\
(0.227)\end{array}$ & $\begin{array}{l}0.381^{*} \\
(0.195)\end{array}$ \\
\hline Migration duration & $\begin{array}{l}0.026^{* * *} \\
(0.010)\end{array}$ & $\begin{array}{c}-0.009 \\
(0.010)\end{array}$ & $\begin{array}{c}0.008 \\
(0.008)\end{array}$ \\
\hline Male (d) & $\begin{array}{l}0.407^{* *} \\
(0.203)\end{array}$ & $\begin{array}{r}-0.059 \\
(0.185)\end{array}$ & $\begin{array}{c}0.144 \\
(0.186)\end{array}$ \\
\hline Age at arrival & $\begin{array}{r}0.023^{*} \\
(0.012)\end{array}$ & $\begin{array}{c}-0.001 \\
(0.011)\end{array}$ & $\begin{array}{l}0.019^{* *} \\
(0.008)\end{array}$ \\
\hline $\begin{array}{l}\text { Intermediate or vocational } \\
\text { secondary degree (d) }\end{array}$ & $\begin{array}{c}0.042 \\
(0.192)\end{array}$ & $\begin{array}{c}0.159 \\
(0.208)\end{array}$ & $\begin{array}{c}0.295 \\
(0.218)\end{array}$ \\
\hline Secondary degree $(b a c)(\mathrm{d})$ & $\begin{array}{c}0.282 \\
(0.230)\end{array}$ & $\begin{array}{c}0.111 \\
(0.251)\end{array}$ & $\begin{array}{c}0.215 \\
(0.356)\end{array}$ \\
\hline University degree (d) & $\begin{array}{r}-0.160 \\
(0.213)\end{array}$ & $\begin{array}{c}0.099 \\
(0.215)\end{array}$ & $\begin{array}{c}0.269 \\
(0.433)\end{array}$ \\
\hline Italy (d) & $\begin{array}{r}0.292^{*} \\
(0.160)\end{array}$ & $\begin{array}{c}0.189 \\
(0.167)\end{array}$ & \\
\hline Cote d'Ivoire (d) & & & $\begin{array}{c}0.223 \\
(0.163)\end{array}$ \\
\hline Constant & $\begin{array}{l}-2.499^{* * *} \\
(0.427)\end{array}$ & $\begin{array}{l}-1.073^{* * *} \\
(0.395)\end{array}$ & $\begin{array}{l}-2.176^{* * *} \\
(0.343)\end{array}$ \\
\hline $\begin{array}{l}\text { Observations } \\
\text { Pseudo } R^{2}\end{array}$ & $\begin{array}{l}428 \\
0.054\end{array}$ & $\begin{array}{l}428 \\
0.023\end{array}$ & $\begin{array}{l}539 \\
0.032\end{array}$ \\
\hline
\end{tabular}

Robust standard errors in parentheses

$+p<0.15,{ }^{*} p<0.10,{ }^{* *} p<0.05,{ }^{* * *} p<0.01$

(d) for dummy variables 
Europe, although the coefficient on network help is not significant in the latter case.

I tested alternative specifications, not shown here, including unemployment data at a disaggregate level as additional controls to account for labor market conditions at the time the migrant first arrived in the host country, for the French and Italian sub-samples only due to data availability. I find no correlation between local unemployment rate and the probability to experience mismatch, and controlling for unemployment does not affect the coefficients on network help. Note that this result is consistent with the absence of long-term effects of unemployment at arrival on immigrants' labor market status found in Chiswick, Cohen, and Zach (1997).

It could be argued that host language proficiency should be included in the set of control variables. Indeed, as shown by Dustmann and Soest (2002), language proficiency increases immigrants' earnings. However, although information on the language spoken at home is available in the MIDDAS survey data, it cannot be exploited for three reasons: first, it is at best a very imprecise proxy of language proficiency. Indeed, answers are heavily dependent on the structure of the household in the country of destination ${ }^{7}$. Second, migrants in the four countries of the survey cannot be compared in that respect. A large majority of migrants in France speak French due to the historical links between France and Senegal and the place of the French language in the formal education system in Senegal. By contrast, very few Senegalese in Italy speak Italian. Language proficiency cannot be controlled for since it is too much correlated with the country dummies in the European subsample. In the two African countries, the official language (Arabic in Mauritania, French in Côte d'Ivoire) coexist with several other languages spoken by large shares of the population, making the notion of host language proficiency more complex to measure and not captured by the spoken at home language. Third, as noted by Dustmann and Soest (2002), language proficiency is unlikely exogenous, and may be correlated with the same unobservable individual characteristics that drive occupational

\footnotetext{
${ }^{7}$ For example, a migrant living with Senegalese from the same ethnic group (for example family members), say Wolof, will very likely report to speak Wolof at home, even if she is perfectly fluent in French.
} 
mismatch. Because of these limitations, I stick with the specification including migration duration, education dummies and country dummies which are likely to capture most of the language proficiency effect.

As discussed above, the results from the standard probit estimations are likely to be biased. For example, if among migrants those with the highest unobserved skills (social skills, motivation,...) are also those who are the most likely to get a job through their Senegalese contacts then for example, the negative coefficient on the network help dummy in the negative mismatch equation, in table 1 (column 2), may merely reflect the fact that those migrants with the highest unmeasured ability are both more likely to use their connections to find a job and to get a job which matches their productive skills.

\subsection{Instrumental variable results}

\subsubsection{OLS First-stage results}

Table 3: First stage regressions of network help to a job on instruments; France and Italy

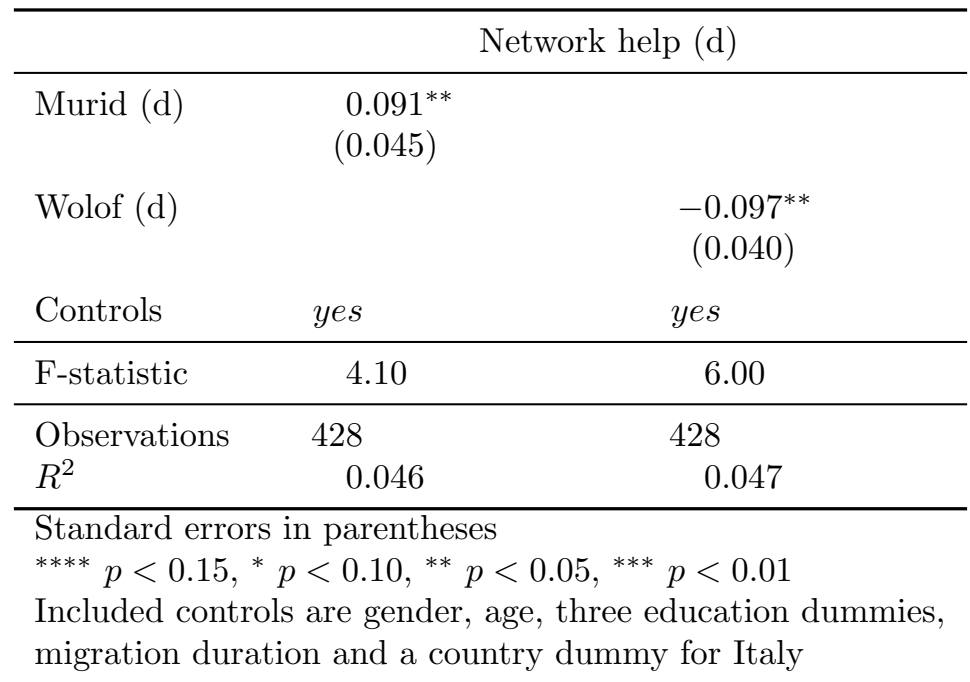

Table 3 presents first stage results for the Mouride and Wolof instruments on the subsample of migrants surveyed in France and Italy. The dependent variable in both columns is a dummy variable that equals one if the migrant has obtained her current job through the migrant network. Individual characteristics (gender, age and education) and 
migration duration are controlled for. A dummy for Italy is also included.

The coefficients on the instruments have the expected signs and are both significant. Being affiliated to the Mouride brotherhood is positively correlated with the probability to have obtained one's current job through the migrant network. On the other hand, the Wolof dummy is negatively correlated with network help, which seems to support the intuition that Wolof migrants may benefit from smaller or less efficient networks. Although the coefficients on both instruments are significant at the $5 \%$ level, the Fstatistics are low, suggesting that the chosen instruments are valid but weak (based on the tables provided by Stock and Yogo (2005)). The IV coefficients in the second-stage regressions may thus be biased (Bound, Jaeger, and Baker, 1995). Since just-identified models are less biased, even with weak instruments, and since both instruments are correlated I estimate the model using one instrument at a time. Moreover the comparison of second-stage results with varying instruments and different estimation models (IV and bivariate probit) allows to assess the robustness of the results.

\subsubsection{Bivariate probit and linear IV estimation for mismatch}

Second-stage IV and bivariate probit results are presented in table 4. Note that IV results are given in table 4 as a basis for comparison but since both variables are discrete, results from the bivariate probit estimation are more reliable. Reported values for the bivariate probit specifications are average treatment effects corresponding to the average marginal effects of having obtained one's job through the migrant network.

Results presented in table 4 suggest that network help increases the probability of horizontal occupational mismatch but decreases the probability of negative mismatch. Compared with the standard probit results presented in table 1, the effect of network help on negative mismatch remains negative and significant but the positive impact of network help on horizontal mismatch is now significant when network help is instrumented by the Mouride variable. The coefficients estimated with IV models are not significant, but the magnitude of the network effect is very similar in IV and bivariate probit specifications, 
Table 4: Network help and mismatch: IV and biprobit estimates; France and Italy

Horizontal mismatch

Negative mismatch

(1)

(2)

(3)

(4)

\begin{tabular}{lcccc}
\hline Network help (d) & & & & \\
IV & 0.379 & 0.540 & -0.485 & -0.483 \\
& $(0.471)$ & $(0.476)$ & $(0.464)$ & $(0.443)$ \\
Biprobit & $0.431^{* * *}$ & 0.278 & $-0.491^{* * *}$ & $-0.364^{* *}$ \\
& $(0.057)$ & $(0.234)$ & $(0.035)$ & $(0.182)$
\end{tabular}

\section{Intruments}

Mouride

$X$

$X$

\begin{tabular}{lllll} 
Wolof & & $X$ & & $X$ \\
Controls & yes & yes & yes & yes \\
\hline Observations & 428 & 428 & 428 & 428 \\
\hline
\end{tabular}

Robust standard errors in parentheses

${ }^{+} p<0.15,{ }^{*} p<0.10,{ }^{* *} p<0.05,{ }^{* * *} p<0.01$

(d) for dummy variables

All regressions control for gender, age, education, migration duration and country fixed-effects

and whatever the instrument used, especially as regards negative mismatch.

In sum, although the results shown in this paper should be taken cautiously due to the small size of the sample, using the migrant network to get a job seems to increase immigrants' probability to experience horizontal occupational mismatch. These findings are consistent with the theoretical predictions of the model presented by Bentolila, Michelacci, and Suarez (2010): migrants who obtained their job through their network are more likely to get a different occupation from the one in which they have a productive advantage. However the data that I use do not allow me to discriminate between different possible underlying explanations, such as a higher cost for immigrants to reject a job offer made by his network or the tradeoff between finding a job rapidly and finding a job matching exactly one's skills.

On the other hand, migrant network help decreases the probability of drop in social or occupational status, which is consistent with the theoretical literature modelling the fact that personal referrals reduce uncertainty about migrants productivity and increase the quality of the match. 


\section{Conclusion}

Using data on labor market outcomes of 1,200 Senegalese immigrants I find evidence of an impact of network help on occupational mismatch. Using the ISCO-08 classification, I define horizontal and negative mismatch depending on whether the occupied position and the self-declared occupation in which workers have a comparative productive advantage are associated with similar or different skill levels.

In order to account for potential endogeneity biases due to omitted variables affecting both migrants' probability to be helped by their network and migrants' status on the labor market, I exploit information on their religious affiliation and ethnic group to assess the impact of an exogenous variation in the probability to be helped by the migrant network to get their current job on the probability to experience horizontal and negative mismatch.

I find that migrants who found their current job through a relative or non-related Senegalese are more likely to experience horizontal mismatch: they are more likely to have a job other than the one in which they have a comparative advantage although both require similar skill levels. But they are also less likely to have a job requiring a lower skill level that that of the occupation in which they have a comparative productive advantage.

This paper thus suggests new avenues of research on occupational mismatch not exclusively focused on education.

\section{References}

Aleksynska, Mariya and Ahmed Tritah. 2011. "Occupation-Education Mismatch of Immigrant Workers in Europe: Context and Policies." Tech. rep.

Amuedo-Dorantes, Catalina and Kusum Mundra. 2007. "Social Networks and Their Impact on the Earnings of Mexican Migrants." Demography 44 (4):849-863.

Bava, Sophie. 2003. "De la "baraka aux affaires": ethos économico-religieux et transna- 
tionalité chez les migrants Sénégalais mourides." Revue Européenne des Migrations Internationales 19 (2):69-84.

Bentolila, Samuel, Claudio Michelacci, and Javier Suarez. 2010. "Social Contacts and Occupational Choice." Economica 77 (305):20-45.

Borjas, George J. 1987. "Self-Selection and the Earnings of Immigrants." The American Economic Review 77 (4):531-553.

Bound, John, David A. Jaeger, and Regina M. Baker. 1995. "Problems with Instrumental Variables Estimation When the Correlation Between the Instruments and the Endogeneous Explanatory Variable is Weak." Journal of the American Statistical Association 90 (430):443-450.

Cahuc, Pierre and François Fontaine. 2009. "On the Efficiency of Job Search with Social Networks." Journal of Public Economic Theory 11 (3):411-439.

Chiswick, Barry R. 1999. "Are Immigrants Favorably Self-Selected?" The American Economic Review 89 (2):pp. 181-185.

Chiswick, Barry R., Yinon Cohen, and Tzippi Zach. 1997. "The Labor Market Status of Immigrants: Effects of the Unemployment Rate at Arrival and Duration of Residence." Industrial and Labor Relations Review 50 (2):pp. 289-303.

Chiswick, Barry R. and Paul W. Miller. 2009. "The international transferability of immigrants' human capital." Economics of Education Review 28:162-169.

Clark, Andrew F. 1994. "Internal Migrations and Population Movements in the Upper Senegal Valley (West Africa), 1890-1920." Canadian Journal of African Studies/Revue Canadienne des Etudes Africaines 28 (3):399-420.

Di Pietro, Giorgio and Peter Urwin. 2006. "Education and skills mismatch in the Italian graduate labour market." Applied Economics 38 (1):79-93. 
Dustmann, Christian, Albrecht Glitz, and Uta Schönberg. 2011. "Referral-based Job Search Networks." IZA Discussion Papers 5777, Institute for the Study of Labor (IZA).

Dustmann, Christian and Arthur Van Soest. 2002. "Language and the Earnings of Immigrants." Industrial and Labor Relations Review 55 (3):pp. 473-492.

Goel, Deepti and Kevin Lang. 2009. "Social Ties and the Job Search of Recent Immigrants." Tech. rep.

Granovetter, Mark S. 1974. "Getting a Job: A Study of Contacts and Careers." .

Kugler, Adriana D. 2003. "Employee referrals and efficiency wages." Labour Economics $10(3): 531-556$.

Montgomery, James D. 1991. "Social Networks and Labor-Market Outcomes: Toward an Economic Analysis." The American Economic Review 81 (5):pp. 1408-1418.

Munshi, Kaivan. 2003. "Networks in the Modern Economy: Mexican Migrants in the U. S. Labor Market." The Quarterly Journal of Economics 118 (2):pp. 549-599.

Nordin, Martin, Inga Persson, and Dan-Olof Rooth. 2010. "Education-occupation mismatch: Is there an income penalty?" Economics of Education Review 29 (6):1047-1059.

Robst, John. 2007. "Education and job match: The relatedness of college major and work." Economics of Education Review 26 (4):397 - 407.

Stock, James H. and Motohiro Yogo. 2005. "Testing for Weak Instruments in Linear IV Regression." In Identification and Inference for Econometric Models: Essays in Honor of Thomas J. Rothenberg, edited by J.H. Stock and D.W.K. Andrews. Cambridge University Press. 


\section{Appendix}

Table 5: Summary statistics by host region

\begin{tabular}{|c|c|c|c|}
\hline & $\begin{array}{c}\text { France/Italy } \\
\text { (1) }\end{array}$ & $\begin{array}{c}\text { Mauritania/Côte d'Ivoire } \\
\text { (2) }\end{array}$ & $(3)$ \\
\hline Male $(\%)$ & 76.9 & 71.7 & * \\
\hline Age & 36.7 & 38.1 & $* *$ \\
\hline Migration duration (years) & 11.9 & 10.8 & \\
\hline Age at arrival & 24.8 & 27.2 & $* * *$ \\
\hline No or primary degree $(\mathrm{d})$ & 40.5 & 82.6 & $* * *$ \\
\hline Intermediate or vocational secondary degree (\%) & 24.0 & 11.3 & $* * *$ \\
\hline Secondary degree $(b a c)(\%)$ & 13.6 & 3.6 & $* * *$ \\
\hline University degree (\%) & 21.9 & 2.4 & $* * *$ \\
\hline Mouride (\%) & 41.3 & 37.7 & ** \\
\hline Wolof $(\%)$ & 52.7 & 59.3 & * \\
\hline Italy $(\%)$ & 52.0 & & \\
\hline Côte d'Ivoire (\%) & & 47.3 & \\
\hline Employed (\%) & 72.9 & 86.1 & $* * *$ \\
\hline \multicolumn{4}{|l|}{ Among employed: } \\
\hline Negative mismatch (\%) & 12.7 & 2.2 & $* * *$ \\
\hline Horizontal mismatch (\%) & 14.1 & 11.1 & \\
\hline Network help to find current job(\%) & 19.2 & 15.2 & \\
\hline Hourly wage (PPP) & 9.9 & 3.0 & $* * *$ \\
\hline Monthly wage (PPP) & 1359.6 & 444.7 & *** \\
\hline Observations & 558 & 619 & \\
\hline
\end{tabular}

Notes: $\chi^{2} / \mathrm{t} /$ Fisher mean or proportion tests in column (3)

Source: MIDDAS survey, 2009-2010 
Table 6: Mapping of ISCO-08 major groups to skill levels

\begin{tabular}{lc}
\hline ISCO-08 major groups & Skill level \\
\hline 1 Managers & $3+4$ \\
2 Professionals & 4 \\
3 Technicians and Associate Professionals & 3 \\
4 Clerical Support Workers & 2 \\
5 Services and Sales Workers & 2 \\
6 Skilled Agricultural, Forestry and Fishery Workers & 2 \\
7 Craft and Related Trades Workers & 2 \\
8 Plant and Machine Operators, and Assemblers & 2 \\
9 Elementary Occupations & 1 \\
0 Armed Forces Occupations & $1+2+4$ \\
\hline
\end{tabular}

